\title{
Esquerda ou direita? Professores, opção política e didática da história.
}

\author{
Left or right? Teachers, political options and history didactics.
}

\author{
Caroline Pacievitch 1 \\ Luis Fernando Cerri ${ }^{2}$
}

RESUMO

Discute-se neste texto o tema das opções políticas de professores de história e suas implicações para a docência. Questiona-se: existem relações entre a opção política e as escolhas didáticas de um professor de história? Os dados foram obtidos em colaboração com o projeto Jovens e História no Mercosul, que usa um questionário respondido por uma amostra não probabilística de 288 professores de história do Brasil, da Argentina, do Uruguai, do Chile e do Paraguai. As respostas receberam um tratamento estatístico descritivo e inferencial e atribui-se especial atenção às opções políticas dos professores e aos cruzamentos de informações gerais com posicionamentos sobre aspectos didáticos. A noção de esquerda e direita foi delineada a partir de Norberto Bobbio. Constatou-se que os professores, independente da opinião política, defendem a importância do ensino de história e valorizam sua própria participação política. Há diferenças sutis na avaliação de objetivos de ensino e de dificuldades profissionais entre os docentes, que também tendem a interpretar eventos históricos sensíveis de forma coerente às opções políticas. Essas constatações provocam a pensar o papel dos formadores de professores de história, reforçando a importância de conectar política e didática na constituição da responsabilidade docente.

Palavras-chave: Ensino de história. Formação de professores. Didática da história. Posições políticas. Mercosul.

1 Professora da Área de Ensino de História da Universidade Federal do Rio Grande do Sul.

2 Professor do Departamento de História e dos Programas de Pós-Graduação em Educação e em História da Universidade Estadual de Ponta Grossa 


\begin{abstract}
In this text we discuss the political options of history teachers and its consequences to teaching. We ask if there are relations between political options and didactical choices of the history teacher. The data were obtained from the project "Youth and History in MERCOSUR", that uses a questionnaire which was responded by a sample of 288 history teacher of Brazil, Argentina, Uruguay, Chile and Paraguay. A descriptive and inferential statics treatment was given to the answers, with special attention to political options of the teachers, and crossing general information with stances about didactical aspects. Norberto Bobbio's notion about left and right was used. It was noted that the teachers, regardless of political opinion, defend the history teaching importance and care about their own political participation. There are subtle differences about the teaching objectives evaluation and about professional difficulties among teachers, that also interpret sensitive historical themes coherently to their political stances. These findings invite to think more about the role of those professors who performs history teachers training, as to reinforce the importance of connecting politics and didactics in the making of teaching responsibility.
\end{abstract}

Keyword: History teaching. Teachers training. hiStory didactics. Political stances. Mercosur.

Estudar para ser professor de história é uma variável importante para a definição de um comportamento político? As convicções políticas são, por sua vez, uma variável importante para a definição de estratégias didáticas e concepções de história a embasar as atividades de ensino? Num contexto em que, superficialmente, jornalistas de direita que fazem um jornalismo política e ideologicamente comprometido e movimentos de direita recém organizados cobram isenção e neutralidade da escola, estas e outras perguntas ganham cada vez mais relevância. Para além de um debate político, este artigo pretende contribuir com dados de uma investigação de caráter quantitativo. Obviamente, após todo o conjunto de discussões epistemológicas sobre o papel do sujeito e as condições de enunciação dos discursos na história e nas ciências humanas desde meados do século XX, não temos a pretensão de produzir um discurso de objetividade que paire acima das divisões políticas e sociais. Admitir um posicionamento simpático aos ideais políticos, econômicos e sociais à esquerda, para o debate político rasteiro instalado há poucos anos em parte da imprensa brasileira, é oferecer desde já elementos para a condenação sumária deste texto todo. Longe dessa concepção ingênua e pouco informada sobre as ciências humanas, para nós esse posicionamento é uma condição de honestidade intelectual, que colabora para que o leitor relativize elementos da argumentação, ao mesmo tempo em que permite que se identifiquem pontos de acordo e discordância. 
Os dados foram obtidos em colaboração com o projeto Jovens e História no Mercosul, que envolve pesquisadores de todos os países do bloco, mais o Chile. O projeto consiste em um levantamento de dados a partir de dois questionários, um para estudantes da educação de nível médio e outro para professores de história. O questionário de professores foi respondido por uma amostra não probabilística de 288 sujeitos do Brasil (todas as regiões), da Argentina, do Uruguai, do Chile e do Paraguai. As respostas do questionário receberam um tratamento estatístico descritivo e inferencial, com especial atenção às opções políticas dos professores a partir da questão: "nas eleições, você costuma votar em candidatos e partidos de [...]". As cinco opções de resposta (esquerda, centro-esquerda, centro, centrodireita e direita) foram cruzadas com outras informações gerais de perfil e com posicionamentos sobre aspectos didáticos do trabalho do docente, como objetivos do ensino de história, interesses dos alunos, problemas da profissão. A noção de esquerda e direita que informa este texto foi delineada a partir de Norberto Bobbio (2011), em diálogo com pesquisas sobre formação de professores de história e com investigações sobre cultura política nos países da América Latina.

Para Norberto Bobbio, há quatro possibilidades de organização política entre os dois polos: extrema-esquerda, centro-esquerda, centro-direita e extrema-direita. O que as diferencia é a forma de se posicionar perante o tema da igualdade. Segundo o autor, existe a necessidade não só de debater direita e esquerda, mas de posicionar-se a favor do socialismo liberal ou de um liberalismo social, aproximadamente a tendência verificada em professores participantes de pesquisa qualitativa desenvolvida anteriormente por um dos autores. A liberdade e a igualdade concentrariam a relação primordial para se pensar a direita e a esquerda no mundo. Há quem defenda a validade dos argumentos de Norberto Bobbio (MOREIRA, 2000) e quem considere parcialmente suas propostas, embora reconhecendo o valor de seu pensamento, prefira buscar diferentes categorias para definir opiniões políticas (TAROUCO; MADEIRA, 2013), atentando para o fato de que não é possível transferir conceitos europeus para a realidade latino-americana.

O ponto de partida de Bobbio (2011) era o fato incômodo de que os termos "direita" e "esquerda" eram usados cotidianamente para definir as posições durante as eleições, mesmo que muitos acadêmicos anunciassem a falência desta categorização. Ele também alegava que não faria juízo de valor de nenhum dos termos, evitando pensar que a esquerda representa o mal e a direita o bem ou vice-versa. Outro problema levantado por Bobbio é o de que a crítica às categorias direita-esquerda corresponde a um momento de contração da direita no espaço político europeu, bem como uma recusa a ser identificado como de direita, o que conduziria à contestação da própria possibilidade de existir política partidária no seio da sociedade ocidental. Autores como Edgardo Mocca (2005) demonstram um movimento semelhante ocorrido na Argentina, quando Menem atacou frontalmente a política. Segundo o mesmo autor, uma pesquisa do PNUD de 2001 mostrou que, para 94\% dos participantes, os partidos políticos eram as instituições menos confiáveis. 
Assim, ao mesmo tempo em que surgem formas interessantes e diferentes de se pensar e fazer política, constatam-se discursos que condenam toda e qualquer expressão política, transformando-a em termo que não deveria ser mencionado. Bobbio ainda destaca que a escolha da igualdade como critério de distinção entre direita e esquerda não foi criação dele, mas é um dos critérios clássicos na literatura política. Talvez a diferença esteja na forma como Bobbio (2011, p. 23) concebe essa igualdade na relação com direita e esquerda.

[...] A diferença entre direita e esquerda não se manifesta sob a forma de tensão entre uma igualdade de direita e uma igualdade de esquerda, mas com base no diverso modo em que é concebida, respectivamente pela direita e pela esquerda, a relação entre igualdade e desigualdade. Partindo do pressuposto, como eu fiz, de que a pessoa de esquerda é aquela que considera mais o que os homens tem em comum do que o que os divide, e de que a pessoa de direita, ao contrário, dá maior relevância política ao que diferencia um homem do outro do que ao que os une, a diferença entre direita e esquerda revela-se no fato de que, para a pessoa de esquerda, a igualdade é a regra e a desigualdade, a exceção.

Trata-se da distinção que assumimos para os fins desta pesquisa. Entretanto, é preciso ressaltar que o questionário possui seus limites, pois a pergunta não se referia às posições pessoais do professor, mas, sim, às suas opções de voto. Há que se ponderar que as pessoas votam, em geral, conforme as suas opções políticas e ideológicas, como demonstram alguns pesquisadores (KAUCHAKYE, 2012; TAROUCO; MADEIRA, 2013; DOSEK, 2014; RODRIGUES, 2009; NOLTE, 2004). Assim, considera-se, além das características descritas acima, que pessoas de direita e esquerda também se distinguem pelas decisões que tomam perante dilemas de justiça e de igualdade (BOBBIO, 2011, p. 24).

Talvez o argumento mais importante de Bobbio (2011) para esta pesquisa resida na importância de verificar o posicionamento não apenas em si, utilizando parâmetros préestabelecidos, mas em cruzar as respostas dos professores sobre o voto com outras opiniões e, assim, verificar se há correlações possíveis entre ser um professor que vota à direita, ao centro ou à esquerda e suas tomadas de decisão sobre ensinar história. Derivando esse pensamento para o presente estudo, não é possível criar um quadro único de características de um professor de esquerda ou de direita, mas, sim, comparar opiniões e decisões conforme a autoidentificação do grupo concreto de docentes cujas respostas foram disponibilizadas nos questionários. 
Uma das principais dificuldades registradas pelos pesquisadores lidos na revisão de literatura que acompanhou esta pesquisa é definir o que é direita ou esquerda e captar, nos instrumentos de coleta de dados, o posicionamento político. Assim, diversas das pesqui sas estudadas procuraram combinar a autodeclaração com a formulação de situações-problema hipotéticas que exigem tomadas de decisão. Os autores avaliam se o participante se dirige mais à direita ou mais à esquerda pelo conjunto das respostas oferecidas (CARREIRÃO, 2002), comparando programas de partido com votações de políticos (KAUCHAKJE, 2012), ou ainda analisando discursos de meios de comunicação (MOTTA; POSSENTI, 2008).

Não foi possível encontrar pesquisas tratando da identificação política de professores de história envolvendo países do Mercosul, embora haja trabalhos que analisam políticas educacionais na região a partir de perspectivas de esquerda, assim como pesquisas que tratam de verificar o viés ideológico das políticas educacionais no Brasil (GOUVEIA, 2009). Cabe mencionar o estudo comparativo de Fanfani (2007) que, embora não tenha incorporado as variáveis que nos interessam (disciplina de especialidade do professor e opções políticas nas eleições), apresenta dados significativos para pensar o tema aqui proposto. Por exemplo, instados a optar pelo valor mais importante entre liberdade e igualdade (com a terceira opção de não estar de acordo com a prevalência de uma ou outra e ainda não responder), a ampla maioria dos professores na amostra brasileira de Fanfani $(74,5 \%)$ escolhe a igualdade. Na Argentina e no Uruguai, a distribuição é mais ou menos equivalente, com leve vantagem para a igualdade. Não há dados sobre o Paraguai ou o Chile, que não compuseram a amostra do estudo (FANFANI, 2007, p. 199).

Procurou-se conhecer textos que se dedicassem a entender as noções e manifestações de direita e esquerda na região, a partir de diferentes estratégias teórico-metodológicas. Uma pergunta que persegue diversos estudos, de diferentes formas, gira em torno do papel da esquerda hoje em países como Brasil, Argentina, Bolívia e Uruguai, que passam ou passaram por uma sequência de governos entendidos como de esquerda. Constanza Moreira (2000) acredita que a esquerda no Brasil e no Uruguai passou por três ondas: o sindicalismo do início do século $\mathrm{XX}$, a luta armada durante a Guerra Fria e, por fim, a contraposição ao neoliberalismo, concluindo que se trata de uma esquerda "estatista, movimentista, keynesiana, social-democrata, essencialmente política e tem - como sempre - uma ampla capacidade de mobilização entre os movimentos sociais" (MOREIRA, 2000, p. 18). Apesar dessas semelhanças, a autora visualiza diferenças grandes pelo fato de o Brasil ser uma democracia mais nova e com partidos pouco institucionalizados, se comparado ao Uruguai. Ela também percebeu que a satisfação com a democracia é muito maior no Uruguai do que no Brasil. É oposto também o interesse pela política de cada população. No Uruguai, quem é de esquerda sente-se bem representado pelos partidos de esquerda. No Brasil, é o contrário, quem é de direita é que está satisfeito com seus partidos - pelo menos no final dos anos 1990. 
Detlef Nolte (2004, p. 102) analisou diferentes instrumentos criados pelo Latinobarómetro (CORPORACIÓN LATINOBARÓMETRO, 2015) para verificar a confiança dos latino-americanos na democracia e comparar a vida política em Brasil, Argentina, Chile e Uruguai no início do século XXI, notando apreço e ao mesmo tempo desconfiança em relação à democracia e certa má-vontade com aspectos restritivos de reformas de tipo neoliberal. Em sua visão, direita e esquerda ainda são conceitos válidos para se pensar a política nesses países, embora seja muito importante notar as diferenças. O Brasil tem um espectro de partidos bem mais amplo que o da Argentina. As clivagens entre direita e esquerda no Chile são bem grandes, sendo também notáveis no Uruguai e menos intensas no Brasil. Já na Argentina isso é bem mais difícil (NOLTE, 2004, p. 107).

Los datos para Argentina confirman la valoración de muchos analistas de que es difícil discriminar entre los partidos políticos argentinos en base de un esquema izquierda-derecha. Las bancadas en el Senado de los dos grandes partidos tradicionales argentinos, UCR y PJ, se diferencian poco entre sí respecto a su posicionamiento en la escala izquierda-derecha. Los otros partidos como el FREPASO tienen mucho menos peso político y/o son limitados en su base de apoyo territorial (como los partidos provinciales).

Argentinos e uruguaios, segundo o mesmo pesquisador, estariam mais dispostos a um Estado interventor na economia do que brasileiros e chilenos. Ao fim, Nolte (2004, p. 118-120) conclui:

[...] Parece que los parlamentarios y los ciudadanos en América Latina (o al menos en los países del Cono Sur incluidos en nuestro estudio) usan un mapa mental común para orientarse en el paisaje político. De esta manera, es posible ubicar a todos los partidos incluidos en nuestro estudio en una dimensión izquierda-derecha, basada tanto en la clasificación de sus propios militantes y representantes (senadores y diputados), como en los esquemas políticos usados por los ciudadanos y votantes. Salvo muy pocas desviaciones, el desplazamiento y la secuencia de los partidos políticos es visto de la misma manera a nivel de élites y ciudadanos. [...] Por lo menos en tres de los cuatro países analizados - Argentina es la excepción - los partidos políticos representados en el Senado ofrecen a los electores una oferta 
diferenciada respecto a su posicionamiento en una dimensión izquierda-derecha $y$ en varios temas de política socioeconómica. Además en Argentina muy pocos electores declaran una preferencia por un partido político y se autoposicionan en el espacio izquierdaderecha. En los otros casos, la dimensión izquierda-derecha funciona como una coordenada para orientarse en la política, pero no es necesariamente la única.

Essa diferença entre os cidadãos argentinos e os demais seria relevante também entre os professores de história, que compartilham certas referências comuns? Eis outra pergunta a dirigir para os dados que serão apresentados adiante.

Bresser-Pereira (2000), na mesma época, preocupava-se não só em definir o significado geral de esquerda, mas em analisar a esquerda no Sul do mundo depois do fim da União Soviética, isto é, no mesmo momento em que Moreira (2000) localizou o último estágio da esquerda no Brasil e no Uruguai. Utilizando o apego à ordem (e não à igualdade) como critério para definir direita e esquerda, Bresser-Pereira (2000, p. 156-p. 175) indica algumas características do que ele chama de Nova Esquerda no mundo.

[...] A Nova Esquerda que emergiu da crise do Estado e do colapso da União Soviética de 1989, e que ganhou eleições, ainda visa ao socialismo, mas frequentemente evita a palavra, dada a sua conotação estatista. $O$ socialismo democrático segue sendo um objetivo, mas $o$ socialismo é definido em novos termos, enfatizando seu caráter radicalmente democrático. $\mathrm{O}$ socialismo será consistente com um sistema econômico de mercado coordenado, onde prevalece um sistema democrático, uma vez que somente através da igualdade política será possível alcançar ampla igualdade de oportunidade e a proteção aos incapazes de competir no mercado - as duas características que distinguem o socialismo. [...] Essas características da Nova Esquerda - orientada para o mercado, comprometida com a reconstrução da capacidade do Estado e com a redução das desigualdades sociais - são as que serão mais requisitadas no século XXI. É por isso possível prever que modernos partidos políticos socialdemocratas tenderão a estar no poder com mais assiduidade do que costumavam no século XX. 
As previsões de Bresser-Pereira teriam se realizado? Efetivamente, partidos com tendências socialistas e democráticas ocupam maior espaço político no século XXI? Em 2006, o mesmo autor parece criticar esse olhar, ao preocupar-se com uma esquerda que ocupa o poder político, mas possui grande dificuldade de governar (BRESSER-PEREIRA, 2006). Outras pesquisas ainda mais recentes, como as de Domingo Lilón (2012, p. 2), mostram que faz sentido pensar que existem governos de esquerda muito fortes na América Latina na última década.

Já Zechmeister e Corral (2010), baseadas no Barômetro das Américas (PROYECTO DE OPINIÓN PÚBLICA DE AMÉRICA LATINA, 2015) identificaram que a maioria dos cidadãos entrevistados localiza-se ao centro. Adiante será possível verificar se isso se confirma nos posicionamentos específicos de professores de história. El Salvador, Nicarágua e Uruguai são os países que mais se situam à esquerda. México, Costa Rica e Colômbia são os que ficam mais à direita. Cerca de $20 \%$ dos entrevistados não responde à pergunta sobre a orientação à direita ou à esquerda, que é aproximadamente o mesmo nível do Eurobarômetro. As autoras levam em conta opinião sobre o papel do Estado e sobre a economia (livre comércio) para definir direita e esquerda. Reafirmam, conforme a orientação perseguida nesta pesquisa, que, embora não haja $100 \%$ de coerência entre os respondentes dos surveys, tratar de direita e esquerda ainda faz sentido.

Ainda mais recente é o trabalho de Tomás Dosek (2014), que procura responder à pergunta "por que as pessoas votam na esquerda?". Para isso, analisa duas reeleições: de uma esquerda mais radical na Bolívia (Evo Morales que sucede ele mesmo) e de uma esquerda moderada no Uruguai (Mujica que sucede Tabaré Vázquez). Pergunta: as razões do voto para uma esquerda moderada e para uma esquerda radical são diferentes (DOSEK, 2014, p. 775-776)?

El argumento principal es el siguiente: existen importantes diferencias entre las izquierdas de acuerdo a las motivaciones de voto y los vínculos con los representantes y que éstas radican en el peso de los elementos programáticos y la ideología en la decisión electoral de los votantes. A su vez, esto se deriva de las diferencias de tipo más estructural y las propias experiencias que vivieron los sistemas de partidos en los respectivos países. Asimismo, se sostiene que el voto retrospectivo, entendido como la evaluación del desempeño del gobierno en el poder respecto de varias cuestiones en debate, tiene un peso significativo en la decisión electoral en la mayoría de los casos de las izquierdas latinoamericanas contemporáneas. 
Dosek (2014) repassa as diversas hipóteses, na literatura, sobre a ascensão da esquerda na América Latina: queda do Muro, crítica ao neoliberalismo pela manutenção da pobreza, crise de paradigma, mobilização de setores populares, a aceitação das eleições como forma de chegar ao poder (por parte das esquerdas), ascensão de novos atores sociais, crise dos partidos tradicionais, líderes de esquerda mais gregários. Estas hipóteses, assinaladas em trabalhos qualitativos, são corroboradas por trabalhos de tipo quantitativo, principalmente em relação ao "castigo" ou "recompensa" a governos que atingem ou não as expectativas da população, mas sem dar carta branca para uma revolução total.

O cidadão do Uruguai, nos vários estudos revisados por Dosek (2014), é apontado como um dos que tem maior clareza sobre direita-esquerda e que faz voto ideológico. No caso do Brasil, os programas de distribuição de renda beneficiaram Lula, mas não seu Partido. Esses programas são pouco significativos tanto para Bolívia quanto para Uruguai, diferente da Venezuela. Na Bolívia, o aspecto étnico é muito importante. No Uruguai, variáveis como renda e educação não importam na hora de decidir o voto. Na Bolívia, sim.

Apesar dessas semelhanças, assim como outros autores já mencionados, é preciso tomar cuidado com modelos únicos para todos os países. Os modelos aqui revisados são feitos por especialistas em ciência política e em estatísticas. É importante lembrar que os questionários do Projeto Jovens e História no Mercosul não tinham a mesma intenção, por isso, as perguntas desta pesquisa não são as mesmas dos trabalhos de ciência política aqui apresentados, mas, sim, dedicados à didática da história e, no presente caso, preocupadas com possíveis derivações para a formação de professores.

Para finalizar, é preciso decidir se faz ou não sentido comparar posicionamento político de professores de história de países que, apesar das semelhanças, possuem histórias políticas tão diferentes entre si. Vejam-se os argumentos de Gabriela Tarouco e Rafael Madeira e Tarouco (2011) e Tarouco e Madeira (2013). Para esses pesquisadores, tratar de esquerda e direita ainda é relevante, mas não se podem usar os mesmos parâmetros usados em surveys europeus (MADEIRA; TAROUCO, 2011, p. 179).

[...] Parte-se aqui do pressuposto de que, desde que se preste atenção para a existência de possíveis local policy dimensions e para o peso relativo de cada dimensão (políticas social, econômica, étnica, etc.) em cada país, é possível a realização de uma análise comparativa.

Os partidos não apenas se posicionam à direita ou à esquerda, mas oferecem agendas políticas distintas. Eles são contrários a análises da ideologia de um partido apenas pela 
forma como votam seus representantes no parlamento. Mesmo assim, arriscaram descrever as categorias para direita e esquerda, começando com direita (TAROUCO; MADEIRA, 2013, p. 97):

[...] menções positivas às forças armadas, livre iniciativa, incentivos, ortodoxia econômica, limitação do Welfare State e referências favoráveis à classe média e grupos profissionais (para contrastar com as referências à classe operária). As categorias selecionadas como indicativas de posicionamento à esquerda são a seguintes: regulação do mercado, planejamento econômico, economia controlada, análise marxista, expansão do Welfare State e referências positivas à classe trabalhadora.

Por fim, os pesquisadores alertam que há grande diversidade proposta pela literatura especializada quanto à forma de aferir se um partido é de direita ou de esquerda. Mas, dada a fluidez das categorias, todas as possibilidades tem seus defeitos e limitações (TAROUCO; MADEIRA, 2013, p. 105). Deste pensamento, infere-se que quiçá a melhor forma seja aquela coerente com os objetivos da investigação e que realize um tratamento ético dos dados obtidos.

No próximo tópico, concretiza-se o trabalho de analisar o posicionamento dos professores de história que concederam suas opiniões ao projeto Jovens e História no Mercosul, procurando por correlações possíveis entre posição política e didática da história.

Os questionários de professores foram coletados juntamente com os de estudantes. Essa coleta foi feita tendo em conta a participação voluntária de pesquisadores e colaboradores em cada cidade na qual se estabeleceu uma parceria. Por isso, no Brasil e na Argentina, em que temos mais adiantada a formação de redes universitárias, a amostra é maior e mais diversificada, ao passo que no Paraguai, Uruguai e Chile, em que essas parcerias estão se iniciando no campo da didática da história, a amostra é bastante restrita. Diante dessas condições, a amostra que foi possível produzir é de caráter não-probabilístico, ou seja, ela 
não tem pretensões de representatividade estatística, embora constitua um caso significativo que permite inferir algumas tendências e perspectivas, apontadas a seguir.

O número total de respondentes variou em cada questão devido aos cruzamentos, pois, por vezes, os professores respondem sobre a opção política, mas não sobre a questão que originou o cruzamento. Para simplificar a visualização, optou-se por não incluir o número de questionários com erros de preenchimento ou em branco. Portanto, ao ler os gráficos e tabelas é preciso lembrar que os percentuais se referem sempre ao número válido de respondentes. Nota-se o quanto as opções de esquerda e centro-esquerda são as favoritas destes professores de história, sempre considerando que eles não poderiam escrever outra possibilidade de filiação política para além das cinco opções oferecidas no questionário. Entretanto, poderiam deixar a resposta em branco, estratégia utilizada apenas por cinco docentes.

Professores de história uruguaios ou chilenos, participantes do projeto "Jovens e História", não votam nem no centro, nem na direita. No caso brasileiro, os docentes que votam em centro, centro-direita e direita, juntos, representam $15,52 \%$ do total. Para os argentinos, são 30,37\%, que é um valor próximo ao quadro paraguaio. Entretanto, não supera os $46,83 \%$ que preferem centro-esquerda, novamente um número muito próximo ao paraguaio. Conforme delineado no subtítulo anterior, as noções de esquerda e de direita também podem variar culturalmente de um país a outro e, além disso, parecem coerentes com o que já se afirmou dos casos paraguaios e argentinos, em outras pesquisas.

O grupo de professores que votam na esquerda e na centro-esquerda no Uruguai são $100 \%$, no Chile são $93,33 \%$, no Brasil são $84,47 \%$ e na Argentina são $69,62 \%$. Poderia se questionar sobre a localização geográfica mais precisa destes professores. Entretanto, não há nenhum município que se destaque por uma correlação maior de forças à direita, à exceção do município de Itá, no Paraguai. Nos demais casos, mesmo quando há um número significativo de professores que afirmam preferir partidos de direita e centro-direita (como, por exemplo, Mar del Plata e São José dos Campos), ainda o número de professores que preferem esquerda e centro-esquerda supera em mais de $50 \%$ os que optam por direita e centro direita, correspondendo aos valores gerais. Mesmo em Itá, o que se nota é equilíbrio nos números, mas não supremacia da preferência por partidos de direita e centro-direita. Tampouco se poderia afirmar que municípios pequenos e interioranos são menos propícios à esquerda e centro-esquerda, ou vice-versa. Não há nichos de preferência à direita, mas se destacam cidades muito diferentes entre si, como Florianópolis, Santiago de Chile, Quilmes, Uberlândia, Belo Horizonte, Brasília, Curiúva, Ituitaba, Itararé e La Plata, onde, para os professores participantes, não há outra opção política que esquerda ou centro-esquerda. Mesmo assim, é preciso ressaltar o caso da Argentina, que acompanha as informações conhecidas na revisão de literatura, onde há maior opção pela direita e centro-direita. Será preciso investigar outros fatores que acompanhem a massiva inclinação por partidos de 
esquerda e de centro-esquerda nesse grupo de docentes que não apenas a região, a começar pelo tipo de escola.

Os números mais expressivos para professores que votam em direita e centro-direita localizam-se nas escolas públicas de periferia e das escolas privadas laicas comunitárias ou alternativas, seguidas das escolas privadas religiosas. Entretanto, não é na pública de periferia em que se encontra o menor número de professores de esquerda e centro-esquerda, mas, novamente, nas escolas privadas laicas, comunitárias ou alternativas. Mesmo assim, em nenhum tipo de escola existe maioria de professores de direita ou centro-direita, nem mesmo acumulando centro, centro-direita e direita e isolando esquerda e centro-esquerda, o mesmo cenário visto na separação por cidade.

Também não se nota diferença em relação ao sexo, como se percebe na tabela a seguir que inclui apenas os professores quem votam em direita e em centro-direita.

Tabela 1 - Professores que votam à direita conforme sexo

\begin{tabular}{|c|c|c|c|}
\hline & Frequência & Percentual válido \\
\hline & Masculino & 11 & 40,7 \\
\cline { 2 - 3 } & Feminino & 16 & 59,3 \\
\hline Total & 27 & 100,0 \\
\hline
\end{tabular}

Fonte: Projeto Jovens e História no Mercosul (2012/13)

A proporção não é diferente da divisão geral entre os sexos somente entre professores que dizem votar em partidos de esquerda e centro-esquerda: $40 \%$ são do sexo masculino e $59 \%$ feminino. Portanto, para este caso, o sexo tampouco é um elemento significativo para explicar diferença de opção política. As pesquisas revisadas na seção anterior também não encontraram conexões possíveis entre sexo e opção política. Elementos mais importantes seriam o grau de instrução e a classe social, que serão observadas adiante.

Com relação à idade, separou-se o total de 275 professores que indicaram este fator por quatro grupos de idade. Não foi possível confirmar o estereótipo que diz que os jovens são mais inclinados à esquerda. No grupo de professores acima de 50 anos é que existe um número significativo de votantes de centro, ao contrário dos demais. Porém, a porcentagem de professores que se localiza à direita ou a centro-direita é a mesma que nos outros grupos de idade. 
Tabela 2 - Opção política em relação à idade. Números relativos.

\begin{tabular}{|c|c|c|c|c|c|}
\hline & $\begin{array}{c}\text { Esquerda } \\
\%\end{array}$ & $\begin{array}{c}\text { Centro-esquerda } \\
\%\end{array}$ & $\begin{array}{c}\text { Centro } \\
\%\end{array}$ & $\begin{array}{c}\text { Centro-direita } \\
\%\end{array}$ & $\begin{array}{c}\text { Direita } \\
\%\end{array}$ \\
\hline 22 a 29 anos & 42,3 & 36,5 & 9,6 & 9,6 & 1,9 \\
\hline 30 a 39 anos & 36,1 & 44,6 & 7,2 & 7,2 & 4,8 \\
\hline 40 a 49 anos & 50 & 38,3 & 6,4 & 3,2 & 2,1 \\
\hline $\begin{array}{c}\text { acima de 50 } \\
\text { anos }\end{array}$ & 35,5 & 26,7 & 26,7 & 8,9 & 2,3 \\
\hline
\end{tabular}

Fonte: Projeto Jovens e História no Mercosul (2012/13)

Com relação ao tempo de experiência, não há grandes diferenças entre ser um professor muito ou pouco experiente. Apenas na faixa etária entre 4 a 8 anos de experiência é que se escolhe mais a centro-esquerda do que a esquerda. Entre os menos experientes, ninguém se qualifica como de direita, mas isso também ocorre com os mais experientes de todos. Assim, não seria o contato com a realidade da escola - mais ou menos prolongado - que determinaria, nesta amostra, um apreço a partidos de direita ou de esquerda.

Dirige-se também um olhar para a formação. Neste caso, dada a diferença entre os formatos de carreiras no Brasil e nos demais países, separaram-se os dados em: possuir formação específica em história e possuir outro tipo de formação, cruzando com a opção política de cada professor.

Tabela 3 - Formação docente inicial e opção política. Números absolutos.

\begin{tabular}{|c|c|c|c|}
\hline \multicolumn{4}{|c|}{$\begin{array}{l}\text { 11. Nas eleições, você geralmente vota em candidatos e partidos de: * } 1 . \text { Qual é sua } \\
\text { formação docente? Geral }\end{array}$} \\
\hline & \multirow[t]{2}{*}{$\begin{array}{c}\text { Com formação específica em } \\
\text { História }\end{array}$} & \multicolumn{2}{|c|}{$\begin{array}{l}\text { Sem formação específica em } \\
\text { História }\end{array}$} \\
\hline & & & Total \\
\hline $\begin{array}{l}\text { Direita e Centro- } \\
\text { Direita }\end{array}$ & 18 & 9 & 27 \\
\hline Centro & 28 & 2 & 30 \\
\hline $\begin{array}{l}\text { Esquerda e Centro- } \\
\text { Esquerda }\end{array}$ & 199 & 24 & 223 \\
\hline
\end{tabular}

Fonte: Projeto Jovens e História no Mercosul (2012/13)

Nota-se que apenas no caso dos professores que votam por direita e centro-direita o número de professores sem formação específica corresponde à metade do número de professores com formação específica em História. Nos outros casos, a proporção é bem menor ( $11 \%$ e $7 \%$, para esquerda/centro-esquerda e centro, respectivamente). Buscaram-se 
ainda outros cruzamentos que identificassem diferenças entre a postura de professores de centro, esquerda e direita. A começar pela pós-graduação, organizada da mesma forma que na tabela anterior: possuir ou não possuir pós-graduação específica em história. Aqui a correlação é menos transparente ainda, pois é preciso lembrar que muitos professores de História realizam pós-graduação em Educação-Ensino de História e não necessariamente em áreas alheias ao seu trabalho. É apenas no caso dos professores que votam em esquerda e centro-esquerda que o número de professores com pós-graduação em História supera o número de professores sem pós-graduação. Entre os docentes que preferem votar em direita e centro-direita, predomina não possuir pós-graduação ou possuí-la fora da área de História.

Há uma significativa diferença na opinião sobre religião. Nos dados gerais, sempre se atribui grande importância à religião, mas encontram-se professores que dizem que a religião é pouco ou nada importante. Porém, isso nunca acontece para os professores que votam à direita e centro-direita. Isso é relevante, e talvez ajude a mostrar consistência nos dados, pois cruza a autodeclaração com uma ideia que é geralmente esperada do posicionamento à direita, pelo menos no Brasil. A média na questão sobre religião, considerando apenas professores que votam à direita e centro-direita é 1,33. Entre os professores que dizem votar em partidos de centro, a média é 1,10. Isto é, nesses dois casos, está acima da concordância. Já entre os professores que votam à esquerda e centro-esquerda, a média é de 0,30. Ainda é positiva, porém, mais próxima da indiferença que do apreço.

Este dado se torna mais significativo ao comparar com o interesse pela política. A média do interesse por política dos professores que afirmam votar no centro é 1,00 , isto é, praticamente idêntico ao interesse por religião e mais próximo de uma afirmação positiva do que da indiferença. A média entre professores que afirmam votar em direita e centrodireita, no interesse pela política, é a mesma do interesse pela religião: 1,3. Ou seja, o interesse é grande pelos dois elementos. Porém, entre os professores de esquerda, o interesse médio por política é de 1,42. Pode ser pequena a diferença em relação aos de direita, mas a diferença é grande em relação à religião. As duas coisas não estão no mesmo patamar, para professores que optam por partidos de esquerda e de centro-esquerda. Entretanto, os dados não permitem corroborar a ideia corrente de que professores à esquerda seriam muito mais interessados por política e, portanto, seriam mais propensos a difundir sua ideologia entre os estudantes.

Para aprofundar um pouco o entendimento sobre isso, direciona-se o olhar sobre a participação na política. Entre os professores de direita, a média é 0,15, isto significa que afirmam ter participado algumas vezes de algum tipo de evento político. Entre os professores de esquerda, a média é ligeiramente maior: 0,43. E os professores que afirmam votar em partidos de centro ficam ainda abaixo afirmando que participaram poucas vezes, com a média de - 0,33 . É diferente do grupo de professores que afirmam votar em direita e 
centro-direita, cujo lado positivo de participação política é maior do que o lado negativo. A maioria dos professores respondeu que participa frequentemente.

Nas tabelas 4 e 5, percebe-se que tanto entre os professores que votam à esquerda quanto entre os que votam à direita, o maior nível está na participação em algumas vezes e bastante próxima da frequente.

Tabela 4 - Sobre a participação na política - Professores que votam na direita e centro-direita.

Sobre sua participação na política - Professores que votam na direita e centrodireita

\begin{tabular}{|c|c|c|c|}
\hline & Frequência & $\begin{array}{l}\text { Percentual } \\
\text { válido }\end{array}$ & $\begin{array}{l}\text { Percentual } \\
\text { acumulado }\end{array}$ \\
\hline Nunca participo & 4 & 14,8 & 14,8 \\
\hline $\begin{array}{l}\text { Participo poucas } \\
\text { vezes }\end{array}$ & 5 & 18,5 & 33,3 \\
\hline $\begin{array}{l}\text { Participo algumas } \\
\text { vezes }\end{array}$ & 6 & 22,2 & 55,6 \\
\hline $\begin{array}{l}\text { Participo } \\
\text { frequentemente }\end{array}$ & 7 & 25,9 & 81,5 \\
\hline Participo sempre & 5 & 18,5 & 100,0 \\
\hline Total & 27 & 100,0 & \\
\hline
\end{tabular}

Fonte: Projeto Jovens e História no Mercosul (2012/13)

Tabela 5 - Sobre a participação na política - Professores que votam na esquerda e centro-esquerda.

\begin{tabular}{|c|c|c|c|c|}
\hline \multicolumn{5}{|c|}{$\begin{array}{l}\text { Sobre sua participação na política - Professores que votam na esquerda e centro- } \\
\text { esquerda }\end{array}$} \\
\hline & \multicolumn{2}{|c|}{ Frequência } & $\begin{array}{l}\text { Percentual } \\
\text { válido }\end{array}$ & $\begin{array}{l}\text { Percentual } \\
\text { acumulado }\end{array}$ \\
\hline Nunca participo & 18 & \multicolumn{2}{|c|}{8,0} & 8,0 \\
\hline Participo poucas vezes & 22 & \multicolumn{2}{|c|}{9,8} & 17,9 \\
\hline $\begin{array}{l}\text { Participado algumas } \\
\text { vezes }\end{array}$ & 73 & \multicolumn{2}{|c|}{32,6} & 50,4 \\
\hline Participo frequentemente & 67 & \multicolumn{2}{|c|}{29,9} & 80,4 \\
\hline Participo sempre & 44 & \multicolumn{2}{|c|}{19,6} & 100,0 \\
\hline Total & 224 & \multicolumn{2}{|c|}{100,0} & \\
\hline n. resp. & 2 & & & \\
\hline Total & \multicolumn{2}{|c|}{226} & & \\
\hline
\end{tabular}

Fonte: Projeto Jovens e História no Mercosul (2012/13) 
Seria preciso ouvir cada um desses professores para caracterizar melhor o que consideram atividades de participação política. Não há dúvida de que uma das representações mais correntes sobre o professor de história encontra-se refletida nessa investigação: de fato, os docentes são muito interessados em política e se identificam majoritariamente com partidos políticos e candidatos de esquerda e centro-esquerda. Entretanto, deve-se ressaltar que os professores que se identificam com a direita afirmam possuir uma participação política tão ativa quanto os demais. Ademais, como se demonstrou, não se trata de um professorado jovem, que poderia justificar uma ilusão pela política que se desfaria com o tempo. Cabe, novamente, a ressalva de que, dadas as especificidades do espectro político em cada país, não é possível generalizar as definições de cada posição política, o mesmo ocorrendo com as comparações entre as amostras dos países selecionados, nesse quesito.

Neste momento, se ensaiam alguns cruzamentos entre a opinião política dos professores e a didática da história. Nenhum professor, independente da opção política, afirmou que a importância da história é "muito pequena" na vida dos alunos. Em todos os casos, o valor que prevalece é o "muito grande". O que varia, portanto, não é a importância da história e, sim, a forma como cada professor escolhe ensiná-la e a ênfase que atribui a cada tipo de objetivo.

Para visualizar estes aspectos, é necessário aproximar-se mais da sala de aula, dentro das possibilidades que o questionário oferece. A tabela 6 , a seguir, informa como os professores julgam que são suas aulas, cruzando com a opção política.

Em quase todos os casos as respostas oscilam do "às vezes" ao "frequente" 3 , sendo que o grupo centro-direita e direita está mais próximo do "às vezes" e centro-esquerda e esquerda mais próximo do "frequente", ficando os professores que afirmam preferir partidos de centro entre essas duas opções. Entretanto, não se pode afirmar que haja intensa diferença de posicionamento conforme as opiniões políticas dos docentes. As estratégias mais utilizadas em sala de aula, por todos os professores, são a leitura de material didático (13g), as exposições orais (13a) e o uso de diferentes fontes históricas (13d).

\footnotetext{
${ }^{3}$ A escala era: nunca, quase nunca, às vezes, frequentemente, quase sempre.
} 
Tabela 6 - O que acontece nas aulas com mais frequência, conforme opção política. Média.

\begin{tabular}{|c|c|c|c|c|c|c|c|c|}
\hline \multicolumn{10}{c|}{ O que acontece nas aulas com mais frequência? * Opção política. Médias } \\
\hline
\end{tabular}

Fonte: Projeto Jovens e História no Mercosul, 2012/13

Porém, o equilíbrio entre direita, centro e esquerda não é regra para todos os casos. Os professores de centro são os que mais afirmam trabalhar com documentos históricos e ilustrações, seguidos dos professores à esquerda e, por último, dos professores que optam à direita. A diferença não é expressiva, mas chama a atenção o cuidado desses professores com o uso de fontes, coerente com o baixo grau de concordância com a questão 13b.

Já os professores que optam por partidos de direita e centro-direita são os que mais afirmam realizar atividades com a comunidade, dramatizações e saídas a campo (13h), com um valor bem acima dos demais. Eles também informam que é frequente que seus alunos sejam informados sobre o bom e o mau, o certo e o errado na história (13b), pois uma interpretação mais progressista do ensino de história preferiria que os alunos reinterpretassem a história (13e) ou que discutissem diferentes explicações sobre o passado (13c), questões em que os professores à esquerda apresentam maiores médias. Quiçá a menor atenção, por parte dos professores de centro, esquerda e centro-esquerda às saídas a campo e dramatizações se relacione com o fato de dedicarem-se a outras coisas, que considerem mais próximas a seus objetivos como responsáveis pelo aprendizado histórico dos estudantes.

Em busca de mais indícios das diferenças de posicionamento entre professores com distintas opiniões políticas, procurou-se verificar a leitura que fazem dos interesses de seus alunos.(tabela 7) 


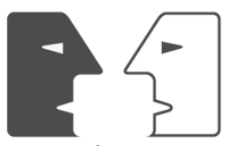

ANTÍTESES

Tabela 7 - Que temas da história mais interessam aos alunos, conforme opção política. Médias

\begin{tabular}{|c|c|c|c|c|c|c|c|c|c|c|c|}
\hline \multicolumn{12}{|c|}{ 15. Quais os temas da história mais interessam a seus alunos? } \\
\hline & 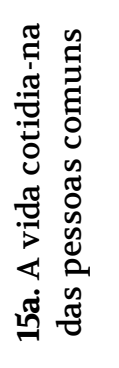 & 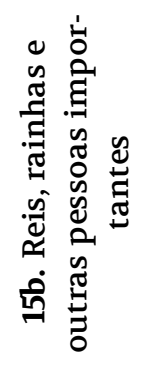 & 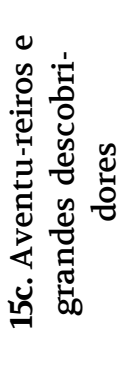 & 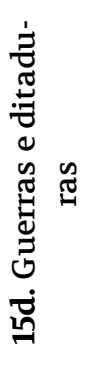 & 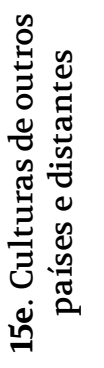 & 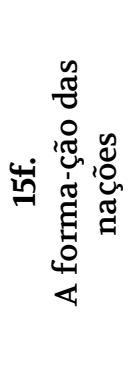 & 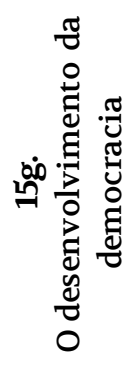 & 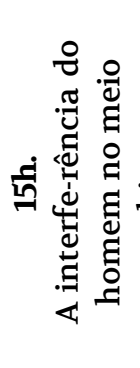 & 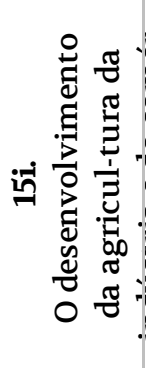 & 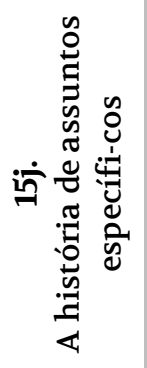 & 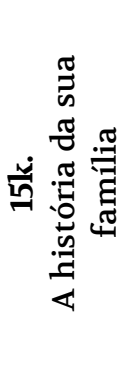 \\
\hline 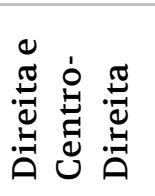 & $-0,11$ & $-0,15$ & 0,56 & 1 & 0,19 & $-0,26$ & 0,3 & 0,11 & 0,04 & 0,22 & 0,04 \\
\hline $\begin{array}{l}\stackrel{\Xi}{\Xi} \\
\text { Uే }\end{array}$ & 0,37 & 0,07 & 0,23 & 0,83 & 0,33 & $-0,24$ & 0,4 & 0,27 & $-0,17$ & 0,3 & 0 \\
\hline 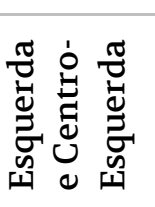 & 0,4 & 0,08 & 0,45 & 1,18 & 0,37 & $-0,31$ & 0,25 & 0,33 & 0 & 0,51 & 0,3 \\
\hline
\end{tabular}

Fonte: Projeto Jovens e História no Mercosul (2012/13)

Novamente, não há diferenças significativas. Todos os aspectos estão muito próximos da indiferença. Aparentemente, os alunos não se interessam por nada em especial, à exceção de guerras e ditaduras (15d). Também há concordância em que o tema menos in teressante para os jovens é a formação das nações (15f). Via de regra, os níveis de interesse são os mais baixos na opinião dos professores de direita e centro-direita e ligeiramente mais altos para os professores que votam a centro-esquerda e esquerda. Isto poderia ajudar a concluir que, quanto mais se aproxima da esquerda, mais positiva é a interpretação dos professores sobre o interesse de seus alunos.

No interesse atribuído à questão 15a, há maior distância entre professores à direita e os ao centro e à esquerda, justamente no que se refere à vida cotidiana das pessoas comuns. Seria maior justamente porque professores mais à esquerda procuram criar esse interesse, hipótese que valeria também para outros casos, como o de ensinar a história da família (15k), algo que parece menos próximo do campo de interesse de professores de centro, centrodireita e direita? 
Por outro lado, um número intrigante: são os professores que dizem preferir esquerda e centro-esquerda os que atribuem menor grau de interesse de seus alunos pela história da democracia. Embora o intervalo não seja grande, pode-se lançar uma hipótese: provavelmente, o interesse pela democracia demonstrado pelos alunos é bem menor do que eles gostariam que fosse, embora os outros professores, de outras opções políticas, reconheçam que o interesse pela democracia é um pouco maior do que a outros temas, como, por exemplo, a própria família, reis e rainhas e o meio-ambiente. Não está acima, porém, do interesse por aventureiros e grandes descobrimentos, em nenhum caso. Este dado ajuda a pensar que os posicionamentos dos docentes não necessariamente influenciam os estudantes, que aprendem história a partir de múltiplas fontes e não apenas da escola.

Assim, outro aspecto a se discutir, também próximo de interrogantes da Didática da História, são os objetivos para o ensino de história.

Tabela 8 - Objetivos do ensino de história e opção política. Médias.

\begin{tabular}{|c|c|c|c|c|c|c|c|c|c|}
\hline \multicolumn{10}{|c|}{ Objetivos do ensino de história. * Opção política. Médias } \\
\hline & 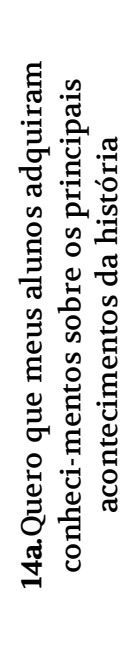 & 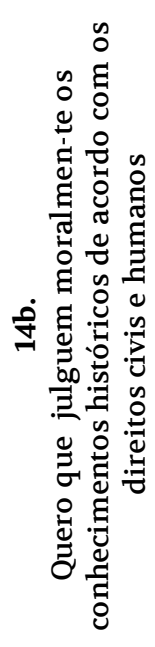 & 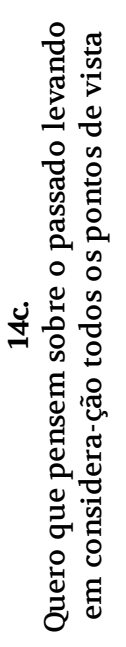 & 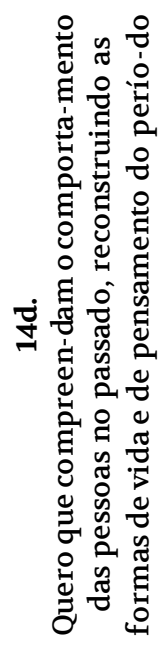 & 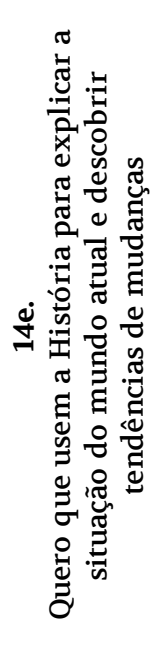 & 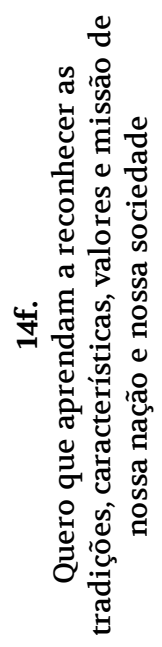 & 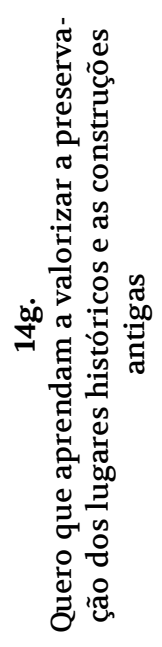 & 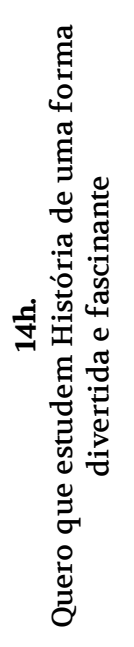 & 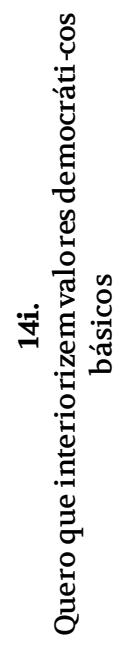 \\
\hline $\begin{array}{c}\text { Direita e } \\
\text { Centro- } \\
\text { Direita }\end{array}$ & 0,96 & 0,73 & 1,00 & 1,19 & 1,56 & 1,3 & 1 & 0,78 & 1,2 \\
\hline Centro & 0,93 & 0,7 & 1,03 & 1,13 & 1,1 & 1,03 & 1 & 0,86 & 1,3 \\
\hline $\begin{array}{l}\text { Esquerda e } \\
\text { Centro- } \\
\text { Esquerda }\end{array}$ & 0,71 & 0,48 & 1,14 & 1,17 & 1,5 & 0,64 & 0,92 & 1,02 & 1,47 \\
\hline
\end{tabular}

Fonte: Projeto Jovens e História no Mercosul (2012/13)

Não há discordância, por parte dos professores, de nenhum dos objetivos mencionados pelo questionário, assim como se nota posição de neutralidade em relação à aquisição de 
conhecimentos e ao julgamento destes conhecimentos frente aos direitos civis e humanos. Os professores que afirmam votar à direita e centro-direita consideram mais importante que os alunos usem a história para entender o momento presente (14e), que reconheçam as tradições, características, valores e missão da nossa nação e da nossa sociedade (14f) e que interiorizem valores democráticos (14i), nessa ordem. Apesar de mencionarem que utilizam estratégias que os alunos costumam gostar (dramatizações, saídas a campo), estão menos preocupados que os demais com que os alunos se divirtam em suas aulas, embora sua indiferença seja um problema para eles, como visto anteriormente. É preciso ressalvar que, entre os professores que optam por direita e centro-direita, quase todos os objetivos estão próximos ao grau 1 . O menor de todos recebeu a média 0,73 e se refere ao julgamento moral dos acontecimentos conforme os valores dos direitos humanos e civis. Ainda assim, diferente da recusa dos professores que optam por esquerda e centro-esquerda. Possivelmente por conta da expressão "moralmente" embutida na pergunta $14 \mathrm{~b}$, a aceitação deste tópico por estes professores foi bem menor que a dos demais. Depois disso, o que os professores à esquerda menos apreciam é o reconhecimento de valores e tradições da nossa nação e da nossa sociedade (14f), justamente no extremo oposto aos professores à direita.

Para os professores à esquerda, o mais importante de todos os objetivos - em escala muito próxima à interiorização dos valores democráticos básicos - é o uso da história para perceber tendências de mudanças. Até aí, pode-se verificar que é o mesmo que entre professores à direita, mas a diferença está na resposta à questão 14f. Ela não está em pé de igualdade com a interiorização de valores democráticos, diferente do que acontece entre professores que votam em centro, direita e centro-direita. A apreciação de diversos pontos de vista também é mais importante para professores que optam por esquerda e centroesquerda do que para os demais, embora com uma diferença muito pequena. Também são estes professores os que menos valorizam (e aqui a diferença é significativa) a aquisição de conhecimentos históricos. Isso talvez seja um problema para a consecução dos demais objetivos, caso a valorização de habilidades de pensamento (como empatia histórica), e a construção de valores democráticos, se façam sem conexão com conhecimentos históricos concretos.

\section{IV}

Outra possibilidade oferecida pelo questionário para a análise do pensamento histórico dos professores participantes são seus posicionamentos sobre fatos do passado que se configuram ainda hoje como questões socialmente vivas: as ditaduras militares e o impacto do Mercosul. 
Tabela 9 - Processos de integração da América do Sul conforme opção política. Médias.

\begin{tabular}{|l|c|c|c|}
\hline \multicolumn{2}{|c|}{ 20. Sobre os processos de integração da América do Sul, que importância tem o } \\
seguinte. Médias
\end{tabular}

Fonte: Projeto Jovens e História no Mercosul (2012/13)

Nota-se uma curva ascendente de concordância nas opiniões dos professores indo da direita para a esquerda. Por vezes, é o centro que mostra maior concordância com aspectos como a mobilidade de estudo, trabalho e transportes (20b e 20c). Nos demais, sã o sempre os professores cujas opiniões políticas estão à esquerda ou centro-esquerda que demonstram entusiasmo ligeiramente maior que o dos demais quanto à integração da América do Sul. Entretanto, não se trata de um fator que divide os professores, pois, ao contrário de outros tópicos, há concordância com as iniciativas que proporcionem maior contato entre os países da região.

Na busca pelas leves diferenças, na esteira do que Tarouco e Madeira (2013, p. 97) identificaram como características de pensamento à direita e à esquerda, a coerência novamente aparece. Os professores que preferem partidos de direita e centro-direita valorizam mais os aspectos econômicos (tópicos 20a e 20b) e o aspecto menos valorizado é o da integração solidária (20d). Os professores de centro posicionam-se entre as grandes obras e a solidariedade entre os países (20b, 20c e 20d). Por fim, aqueles que preferem partidos de esquerda e centro-esquerda valorizam mais a solidariedade e a integração cultural (20d e 20e), o que não significa que desvalorizem a integração econômica.

Assim, nesses pequenos interstícios, é possível verificar a coerência na opinião dos professores à direita e à esquerda, nesse grupo de participantes. Por fim, um olhar para as 
correlações possíveis entre a interpretação desses professores sobre as ditaduras militares e suas opiniões políticas.

Tabela 10 - Opinião sobre os governos militares. Direita e Centro-Direita. Médias.

\begin{tabular}{|l|c|}
\hline \multicolumn{2}{|c|}{ 21. Os governos militares em nosso país podem ser ligados a. Média. Direita e } \\
Centro-Direita
\end{tabular}

Fonte: Projeto Jovens e História no Mercosul (2012/13)

Tabela 11 - Opinião sobre os governos militares. Centro. Médias.

21. Os governos militares em nosso país podem ser ligados a. Média. Centro

\begin{tabular}{|l|c|}
\hline & Média \\
\hline 21b. Intenso desenvolvimento econômico & $-0,55$ \\
\hline 21f. Um período de maior segurança pública & $-0,28$ \\
\hline 21a. Manutenção da ordem e combate ao terrorismo & 0,07 \\
\hline 21e. Crises econômicas e aumento da dívida externa & 1,03 \\
\hline 21d. Não levar em conta a opinião do povo para governar & 1,17 \\
\hline 21c. Tortura e assassinato de opositores & 1,21 \\
\hline
\end{tabular}

Fonte: Projeto Jovens e História no Mercosul (2012/13)

Tabela 12 - Opinião sobre os governos militares. Esquerda e Centro-Esquerda. Médias.

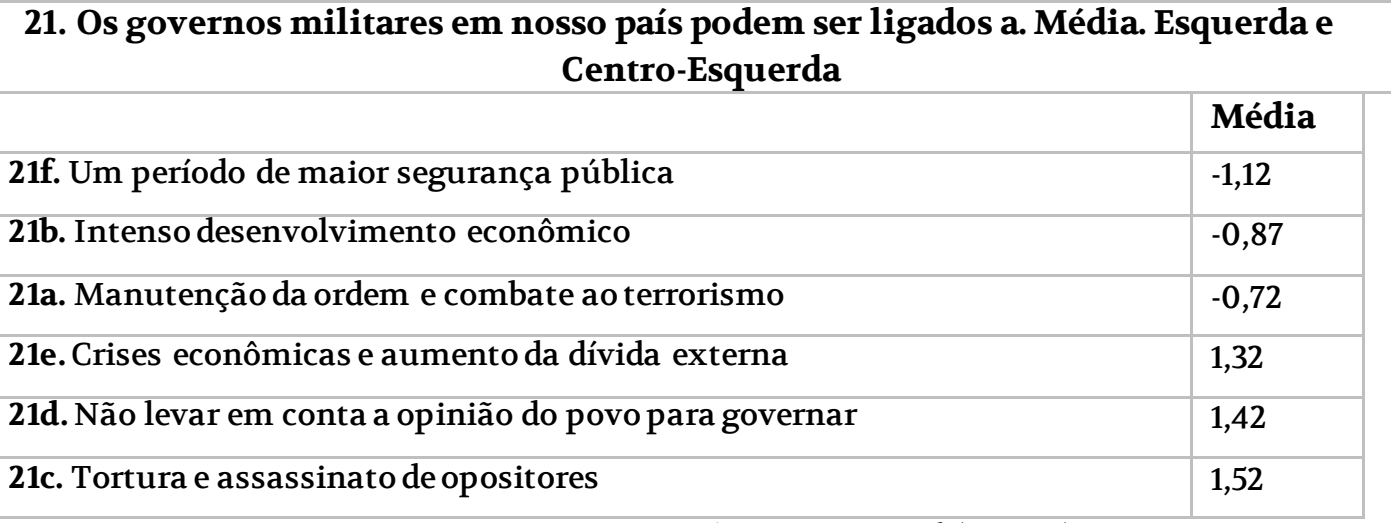

Fonte: Projeto Jovens e História no Mercosul (2012/13) 
Se as diferenças na interpretação sobre a integração do Mercosul eram sutis, aqui elas estão mais evidentes. Em primeiro lugar, na hierarquização dos eventos. As diferenças são pequenas entre direita e centro, mas significativas entre esquerda e direita. Para professores que preferem partidos de direita e centro-direita, é preciso discordar de que o período ditatorial foi de intenso desenvolvimento econômico, em primeiro lugar e, em segundo lugar, de sua eficácia em manter a ordem e combater o terrorismo. Concordam que os militares passaram por dificuldades econômicas e que não consideraram a opinião do povo para governar, sendo esse o caráter de maior concordância nesse grupo de docentes. É importante destacar que a média das respostas ficou mais próxima da indiferença do que de uma concordância ou discordância expressiva.

O mesmo não se pode afirmar dos professores que afirmam votar em partidos de Centro. Para eles, o elemento que mais se destaca no regime militar foi o da tortura e do assassinato e discordam que foi um período de bonança econômica e de segurança.

Já os professores identificados com partidos de esquerda e centro-esquerda são veementes na negação do período ditatorial como um período de segurança pública e acreditam que a tortura e o assassinato são suas maiores marcas, duvidando de sua possibilidade de manter a ordem e combater o terrorismo. Nas respostas dos professores deste grupo, não se notam médias próximas a zero, diferente do centro e totalmente oposto aos professores à direita e centro-direita. Pode ser perigoso generalizar esta conclusão, mas é possível afirmar que há diferenças significativas na interpretação de questões socialmente vivas conforme oscila a opção política desses professores de história, notadamente no que se refere às ditaduras militares, o que, certamente, impacta na seleção de conteúdos e de materiais didáticos veiculados nas aulas, bem como nas finalidades atribuídas ao ensino. Divergências sutis se notam também em respostas referentes aos objetivos do ensino de história. Não se pode afirmar que isso implica em práticas distintas, mas o reconhecimento de oportunidades de formação e o desejo de ter mais tempo para exercer seu trabalho mostram atitudes distintas perante a profissão.

\section{$V$}

A partir do cruzamento das respostas, percebeu-se que não existem relações fortes entre opção política e país, idade, sexo, tipo de escola e tempo de experiência profissional. Possuir formação específica em história tampouco é determinante. Constatou-se que professores que apreciam mais partidos políticos de esquerda ou centro-esquerda - a grande maioria dos participantes - valorizam objetivos do ensino de história ligados à democracia e a 
construção da cidadania crítica, mas isso não significa que os professores que votam à direita e centro-direita os desvalorizem. As diferenças nas escolhas são pequenas, mas existem. Professores à esquerda parecem menos inclinados a transmitir conhecimentos históricos aos alunos e a fazê-lo utilizando recursos como dramatizações e saídas a campo, embora não sejam herméticos ao uso de documentos, filmes, músicas e ilustrações. A avaliação de eventos históricos como a criação do Mercosul e as ditaduras militares também parece realizar-se de forma coerente às opções políticas de cada professor, o que pode impactar na seleção de conteúdos e de recursos didáticos oferecidos aos estudantes.

As pesquisas revisadas demonstraram que é importante, na formação de professores, o compromisso com a tarefa de ensinar história como ação transformadora. Os dados discutidos confirmam e ampliam esta constatação: a inclinação política à direita, ao centro ou à esquerda pode incorrer em pequenas diferenças na forma como esses professores tomariam decisões didáticas, pelo menos dentro dos limites do questionário.

Essas constatações provocam reflexões sobre o papel dos formadores de professores de história, reforçando a importância de conectar política e didática na constituição da responsabilidade docente. Quando se fala em didática da história ou formação de professores, é importante deixar explícito quem são os agentes dessas proposições, para evitar que "a formação de professores" ganhe caráter de sujeito ao invés de identificar pesquisadores, professores universitários, secretários de Educação e deixar apenas os professores como responsáveis pela consecução de projetos utópicos para o ensino de história.

Há que se perguntar sobre a possibilidade de ações escolarizadas formais atuarem como emancipadoras, já que a escola moderna nasce e se desenvolve na tensão entre o novo e o velho, isto é, entre conformar os jovens ao mundo já existente e de permitir que novos conhecimentos sejam construídos (ARENDT, 2009). Essa ideia também pode ser interpretada em uma perspectiva freireana, ou talvez seguindo as construções de Carlo Ginzburg (2012) sobre os múltiplos contatos entre cultura popular e cultura de elite. Nesse jogo, há os que acreditem que é impossível construir mentes livres dentro de muros escolares. Não parece ser esta a tônica predominante entre os pesquisadores da Didá tica da História. Existe uma forte confiança no papel emancipador do conhecimento histórico veiculado nas escolas. Ao ouvir os professores, essa confiança também existe, mas alguns acreditam que isso também depende do seu jeito de ensinar e se consideram frustrados pelas amarras tradicionais que a escola lhes impõe.

Nesse sentido, faria diferença ser um professor de história cujas opiniões políticas estão mais próximas de perspectivas de direita, de centro ou de esquerda? A leitura feita até aqui, dentro dos limites do questionário, indica que, em geral, há muito mais concordâncias do que discordâncias quando se separam as repostas destes três grupos. Retomando nossa questão inicial, verifica-se que a preocupação com política não é um privilégio de 
professores de esquerda, como alguns cuidam denunciar e combater. As compreensões de história e de ensino de história dos professores participantes desta pesquisa estão muito próximas para que se possa constatar uma diferença significativa nas escolhas didáticas. Como é de se esperar, professores que preferem partidos de esquerda e professores que preferem partidos de direita demonstram pequenas nuances nas suas escolhas, o que permite apenas afirmar que há coerência em seus posicionamentos. Não há nada que indique desejo de doutrinação ideológica nem de um lado, nem de outro e, sim, a coincidência na importância da história para a formação dos jovens e o desejo de ensinar da melhor forma possível, denunciando os empecilhos burocráticos e a falta de recursos adequados para tal. Portanto, não seria privilégio de um ou de outro grupo de docentes a presença de traços de seu posicionamento político na vida profissional e esta presença não implicou em variações significativas nas opiniões de cada grupo de docentes, principalmente no que concerne às decisões didáticas, sendo, porém, mais incisivas na interpretação sobre os períodos ditatoriais.

Parece que há elementos mais importantes para nos preocuparmos no que concerne à desejada qualidade no ensino de história: respeitar e reconhecer os professores, garantindolhes condições para desenvolver práticas de ensino de história coerentes com o que aprenderam e com o que sonham para o futuro dos jovens estudantes.

\section{Referências}

ARENDT, H. Entre o passado e o futuro. São Paulo: Perspectivas, 2009.

BOBBIO, N. Direita e esquerda: razões e significados de uma distinção política. São Paulo: Unesp, 2011.

BRESSER-PEREIRA, L. C. O paradoxo da esquerda no Brasil. Novos Estudos, São Paulo, n. 74, p. 25-45, mar. 2006. Disponível em: <http://www.scielo.br/scielo. php?script $=$ sci_arttext\&pid=S0101-33002006000100003>. Acesso em: 9 nov. 2014.

BRESSER-PEREIRA, L.C. A nova esquerda: uma visão a partir do sul. Revista de Filosofia Política, Porto Alegre, v. 6, p. 144-178, dez. 2000. Disponível em: <http://www.bresserpereira.org.br/view.asp?cod=947>. Acesso em: 9 nov. 2014.

CARREIRÃO, Y. S. Identificação ideológica e voto para presidente. Opinião Pública, Campinas, v. $8, \quad$ n. 1 , p. 54-79, 2002. Disponível em: <http://www.scielo.br/scielo. php?script $=$ sci_arttext\&pid=S0104-62762002000100004>. Acesso em: 9 nov. 2014. 
CORPORACIÓN LATINOBARÓMETRO. Latinobarómetro. Disponível em: <http://www.latinobarometro.org/lat.jsp>. Acesso em: 5 fev. 2015.

DOSEK, T. ¿Por qué la gente vota a la izquierda? Clivajes, ideología y voto retrospectivo en Bolivia y Uruguay en perspectiva comparada. Dados: Revista de Ciências Sociais, Rio de Janeiro, v. 57, n. 3, p. 773-815, 2014. Disponível em: $<$ http://www.scielo.br/scielo.php?script=sci_arttext\&pid=S0011-52582014000 300773\&lng=pt\&nrm=iso\&tlng=pt $>$. Acesso em: 16 nov. 2014.

FANFANI, Emilio Tenti. La condición docente. Análisis comparado de la Argentina, Brasil, Perú y Uruguay. Buenos Aires: Siglo XXI Editores, 2007.

GINZBURG, C. Mitos, emblemas e sinais. São Paulo: Cia das Letras, 2012.

GOUVEIA, A. B. Direita e esquerda na política educacional: democracia, partidos e disputas entre projetos de administração pública municipal no Brasil. Revista Brasileira de Estudos Pedagógicos, Brasília, v. 90, n. 224, p. 32-58, jan./abr. 2009. Disponível em: $<$ http://www.oei.es/pdf2/rbep_224_direita_esquerda_politica_educacional.pdf $>$. Acesso em: 9 nov. 2014.

KAUCHAKJE, S. Esquerda e direita importam: partidos políticos e valores de vereadores sobre direitos sociais. Civitas, Porto Alegre, v. 12, n. 2, p. 236-261, maio/ago. 2012. Disponível em: <http://www.redalyc.org/articulo.oa?id =74223598003>. Acesso em: 15 nov. 2014.

LILÓN, D. El mapa político de América Latina en el siglo XXI. South-East Europe International Relations Quarterly, Budapeste, v. 3, n. 2, p. 1-11, 2012.

MADEIRA, R.; TAROUCO, G. Esquerda e direita no Brasil: uma análise conceitual. Revista de Pós-Graduação em Ciências Sociais, Maranhão, v. 8, n. 15, p. 171-186, jan./jun. 2011. Disponível em: <http://www.periodicoseletronicos.ufma.br/ index.php/rpcsoc/article/view/591>. Acesso em: 9 nov. 2014.

MOCCA, E. O futuro incerto dos partidos políticos argentinos. Estudos Avançados, São Paulo, v. 19, n. 55, p. 49-63, 2005. Disponível em: <http://www.scielo.br/scielo. php?pid=S0103$40142005000300004 \&$ script $=$ sci_arttext $>$. Acesso em: 9 nov. 2014.

MOREIRA, C. A esquerda no Uruguai e no Brasil: cultura política e desenvolvimento partidário. Opinião Pública, Campinas, v. 6, n. 1, p. 17-54, 2000. Disponível em: $<$ http://www.redalyc.org/articulo.oa?id=32960102>. Acesso em: 1 nov. 2014.

MOTTA, A. R.; POSSENTI, S. Direita e esquerda: volver! In: JORNADA INTERNACIONAL DE ESTUDOS DO DISCURSO, 1., 2008, Maringá. Anais... Maringá, 2008. Disponível em: 
<http://www.dle.uem.br/jied/pdf/DIREITA\%20E\%20

ESQUERDA\%20motta\%20e\%20possenti.pdf>. Acesso em: 9 nov. 2014.

NOLTE, D. Pautas de orientación socioeconômica y perfil ideológico de los senadores en el cono sur. América Latina Hoy. Salamanca, n. 38, p. 101-123, 2004. Disponível em: $<$ http://revistas.usal.es/index.php/1130-2887/article/viewFile/10321/10749>. Acesso em: 16 nov. 2014.

PROYECTO DE OPINIÓN PÚBLICA DE AMÉRICA LATINA. Barómetro de las Américas. Disponível em: <http://www.vanderbilt.edu/lapop-espanol/acerca-americasbarometer.php>. Acesso em: 5 fev. 2015.

RODRIGUES, L. M. Os partidos brasileiros representam algo? Em direção da estabilização? In: _ _ _ _ _. Partidos, ideologia e composição social: um estudo das bancadas partidárias da Câmara dos Deputados. Rio de Janeiro: Centro Edelstein de Pesquisas Sociais, 2009. p. 143154.

TAROUCO, G.; MADEIRA, R. Esquerda e direita no sistema partidário brasileiro: análise de conteúdo de documentos programáticos. Revista Debates, Porto Alegre, v. 7, n. 2, p. 93-114, maio/ago. 2013. Disponível em: <seer.ufrgs.br/debates/article/ download/38573/26637>. Acesso em: 15 nov. 2014.

ZECHMEISTER, E.; CORRAL, M. El variado significado de "izquierda" y “derecha" en América Latina. Perspectivas desde el Barómetro de las Américas, Nashville, n. 38, p. 1-10, 2010. Disponível em: <http://www.vanderbilt.edu/lapop/insights/I0838es.pdf >. Acesso em: 16 nov. 2014.

Recebido em 27.06.2015

Aprovado em 24.06.2016 